\title{
ENERGY EFFICIENCY OF ROBUST-OPTIMAL SYSTEMS OF CONTROL OF TECHNOLOGICAL OBJECTS
}

\author{
N. Lutska \\ National University of Food Technologies
}

\begin{tabular}{l}
$\quad$ Key words: \\
Robust-optimal regulator \\
Control system \\
Hळ-norm \\
Weight parameters \\
Technological object \\
Energy saving \\
\hline
\end{tabular}

Article history:

Received 08.11.2018

Received in revised form

23.11.2018

Accepted 14.12.2018

Corresponding author:

N. Lutska

E-mail:

lutskanm2017@,

gmail.com

\begin{abstract}
The energy efficiency of robust-optimal control systems for continuous-type technological objects in a dynamic mode, operating in conditions of significant uncertainties is investigated in this paper. The energy efficiency of the control system depends directly on the compromise between quality and power consumption, which is currently provided to the designer of the automation system. The logical improvement of such a system is the construction of an optimization problem for the automatic choice of compromise.

The purpose of the paper is to develop a methodology for choosing an alternative between energy consumption and the quality of the control system, which regulation device is synthesized by the criterion of the Hळ-norm of a closed system in the space of state variables.

The general statement for the problem of robust optimum synthesis of the control device in the space of the state variables is presented, and to the object's mathematical model of which weighted parameters are introduced. The latter are given as real numbers, the fixed fractional-rational transfer functions's coefficients or a set of fractional-rational transmitting functions. Three criteria of energy efficiency have been formed on the basis of the introduced weight parameters that determine the compromise between quality and energy saving of the system. Two of them are reduced to a one-criterion optimization problem with constraints and one to a two-criterion problem based on a stable and effective compromise. Approaches to solving such problems are presented.
\end{abstract}

For example, the robust-optimal regulator according to the Hळ-criterion for a multidimensional technological object was synthesized. The methods of influence on the energy efficiency of the control system are shown and the weight parameters, which were found on the basis of a compromise between energy consumption and system quality were determined. It is proved that such a system is energy-saving, in addition, when minimizing the established criteria, the alternative to the choice facing the designer of the control system is removed.

DOI: $10.24263 / 2225-2924-2018-24-6-4$ 


\title{
ЕНЕРГОЕФЕКТИВНІСТЬ РОБАСТНО-ОПТИМАЛЬНИХ СИСТЕМ КЕРУВАННЯ ТЕХНОЛОГІЧНИМИ ОБ'ЄКТАМИ
}

\author{
Н.М. Луцька \\ Національний університет харчових технологій
}

У статті досліджується енергоефективність робастно-оптимальних систем керування для технологічних об'єктів неперервного типу в динамічному режимі, ще працюють в умовах суттєвих невизначеностей. Енергоефективність системи керування безпосередньо залежить від компромісу між якістю та енерговитратами, який на сьогодні покладений на проектанта системи автоматизації. Логічним вдосконаленням такої системи $\epsilon$ побудова оптимізаційної задачі автоматичного вибору компромісу.

Метою статті є розробка методики альтернативи вибору між енерговитратами та якістю системи керування, пристрій регулювання якої синтезується за критерієм $H_{\infty}$-норми замкненої системи в просторі змінних стану.

Наведена загальна постановка задачі робастно-оптимального синтезу керуючого пристрою в просторі змінних стану, в математичну модель об'єкта якої введені вагові параметри. Останні задаються як дійсні числа, коефіцієнти заданих стійких дробово-раціональних передавальних функцій або множина дробово-раціональних передавальних функиій. Сформовані три критерії енергоефективності на основі введених вагових параметрів, що визначають компроміс між якістю й енергозбереженням системи. Два з них зведені до однокритеріальної задачі оптимізаиії з обмеженнями та один до двокритеріальної задачі на основі стабільно-ефективного компромісу. Приведені підходи до розв'язку таких задач.

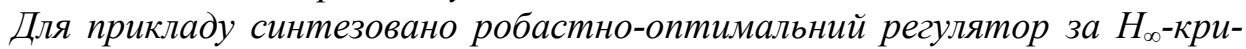
терієм для багатовимірного технологічного об'єкта. Показані способи виливу на енергоефективність системи керування та визначені вагові параметри, що знайдені на основі компромісу між енерговитратами та якістю системи. Доведено, що така система є енергозбережною, крім того, при мінімізаиії сформованих критеріїв знімається альтернатива вибору, щь стоїть перед проектантом системи керування.

Ключові слова: робастно-оптимальний регулятор, система керування, $H_{\infty}$-норма, вагові параметри, технологічний об'єкт, енергозбережність.

Постановка проблеми. Технологічні об'єкти неперервного типу за своєю сутністю є невизначеними. Невизначеності в об'єкті та системі керування обумовлені приблизним математичним описом об'єкта, неточностями вимірювання, нелінійностями керування, введенням нелінійних ланок у систему та багатьма іншими причинами, що лежать в основі функціонування технологічної системи. Значну частину технологічних об'єктів можна умовно розглядати як стаціонарні та лінійні, при синтезі системи керування яких використовуються класичні підходи [1]. Тоді якість та енерговитрати в системі керування незначно змінюються пропорційно зміщенню від прийнятої точки 
лінеаризації. Для об'єктів, які функціонують при суттєвих невизначеностях, класичні методи синтезу призводять до значних втрат якості та енерговитрат. Тож для таких систем ефективними $є$ методи синтезу системи керування, що базується на робастних, адаптивних або інтелектуальних технологіях, для яких окремо постає питання альтернативи вибору між енерговитратами та якістю системи керування.

Один із напрямків синтезу систем керування для об’єктів 3 невизначеностями $\epsilon$ робастно-оптимальні методи. Під останніми розуміються алгоритми розробки керуючого пристрою за робастним критерієм, зокрема $\mathrm{H}_{2}$ - та $\mathrm{H}_{\infty}$-норма передавальної функції, що характеризує систему, наприклад, від вектора входів до вектора виходів замкненої системи, розімкнена система, чутливість системи тощо.

Аналіз останніх досліджень і публікацій. Сьогодні робасно-оптимальний синтез за $\mathrm{H}_{\infty}$-критерієм представлений декількома підходами, наведеними в таблиці, причому перший і третій методи відносяться до структурного синтезу, а 2-, 4- та 5-й методи - до параметричного синтезу. В кожному окремому випадку необхідно обирати альтернативу між якістю системи керування та енерговитратами, адже підвищення енерговитрат веде до збільшення якості перехідних процесів системи керування і навпаки.

\section{Таблиия. Методи синтезу робастно-оптимальних систем керування}

\begin{tabular}{|c|c|c|c|c|}
\hline № & $\begin{array}{l}\text { Назва методу/ } \\
\text { напряму }\end{array}$ & $\begin{array}{c}\text { Літературне } \\
\text { джерело }\end{array}$ & $\begin{array}{c}\text { Математична модель } \\
\text { об’єкта та види } \\
\text { невизначеностей }\end{array}$ & Особливості методики \\
\hline 1 & $\begin{array}{c}\text { Формування } \\
\text { бажаних } \\
\text { властивостей } \\
\text { замкненого } \\
\text { контуру } \\
\text { (Loop shaping) }\end{array}$ & $\begin{array}{l}2, \text { c. } 61 \\
3, \text { c. } 153 \\
\text { c. } 234 \\
1, \text { c. } 411 \\
\quad 4 ; 5\end{array}$ & $\begin{array}{c}\text { Номінальна модель } 3 \\
\text { параметричними, } \\
\text { мультиплікативними та } \\
\text { адитивними } \\
\text { невизначеностями }\end{array}$ & $\begin{array}{c}\text { Вимоги до системи } \\
\text { ставляться в частотній } \\
\text { області, а регулятор } \\
\text { синтезується на основі } \\
\text { взаємно простої } \\
\text { факторизації або інших } \\
\text { методів }\end{array}$ \\
\hline 2 & 2-Ріккаті підхід & $\begin{array}{l}2, \text { c. } 158 ; \\
3, \text { c. } 155 \\
1, \text { c. } 436\end{array}$ & $\begin{array}{c}\text { Номінальна модель, } \\
\text { можливі параметричні } \\
\text { невизначеності }\end{array}$ & $\begin{array}{c}\text { Синтезується центральний } \\
\text { регулятор за алгебраїчними } \\
\text { рівняннями Ріккаті }\end{array}$ \\
\hline 3 & $\mu$-синтез & $\begin{array}{l}2, \text { c. } 207 \\
3, \text { c. } 239\end{array}$ & $\begin{array}{c}\text { Модель зі структурованою } \\
\text { невизначеністю }\end{array}$ & $\begin{array}{c}\text { Базується на понятті } \\
\text { структурованого } \\
\text { сингулярного числа матриці } \\
\text { та теоремі про малий } \\
\text { коефіцієнт підсилення }\end{array}$ \\
\hline 4 & $\begin{array}{c}\text { Метод лінійних } \\
\text { матричних нерів- } \\
\text { ностей (LMI) }\end{array}$ & $\begin{array}{l}2, \text { c. } 180 \\
3, \text { c. } 232 \\
\quad 6\end{array}$ & $\begin{array}{c}\text { Номінальна модель } 3 \\
\text { матричними структурними } \\
\text { невизначеностями }\end{array}$ & $\begin{array}{c}\text { Базується на квадратичній } \\
\text { стабілізації та функції } \\
\text { Ляпунова }\end{array}$ \\
\hline 5 & \begin{tabular}{|c|} 
Метод \\
негладкого \\
синтезу (Non- \\
smooth synthesis)
\end{tabular} & $7 ; 8$ & Номінальна модель & $\begin{array}{l}\text { Ітераційний метод } \\
\text { негладкого синтезу }\end{array}$ \\
\hline
\end{tabular}

Контроль енерговитрат при синтезі робастного регулятора для одновимірних систем відбувається шляхом введення у вихідний вектор контрольованих 
змінних вектора керування, а обмеження його - шляхом вагових функцій при цьому векторі. Однак чітких рекомендацій вибору вагових функцій не існує, зокрема в [9] автор пропонує набір передавальних функцій для конкретного виду сигналу. Для технологічних об'єктів вхідні сигнали розмиті, i ïx лише наближено можна віднести до конкретного виду. Крім того, для багатовимірних систем, для яких задача ставиться та вирішується в просторі змінних стану, питання енергоефективності не розглядалося, а використання векторних частотних передавальних функцій незручне.

Метою статті $\epsilon$ дослідження енергоефективності систем керування, пристрій регулювання якої синтезується за $\mathrm{H}_{\infty}$-нормою замкненої системи в просторі змінних стану, на основі якої розробити методику альтернативи вибору між енерговитратами та якістю системи.

Викладення основних результатів дослідження. Математичну модель технологічного об'єкта керування в номінальному режимі опишемо в просторі змінних стану:

$$
\left\{\begin{array}{l}
\dot{\mathbf{x}}(t)=\mathbf{A} \mathbf{x}(t)+\mathbf{B}_{1}\left[\begin{array}{c}
\mathbf{w}(t) \\
\mathbf{r}(t)
\end{array}\right]+\mathbf{B}_{2} \mathbf{u}(t), \\
{\left[\begin{array}{l}
\boldsymbol{\varepsilon}(t) \\
\mathbf{u}(t)
\end{array}\right]=\alpha\left(\mathbf{C}_{1} \mathbf{x}(t)+\mathbf{D}_{11}\left[\begin{array}{c}
\mathbf{w}(t) \\
\mathbf{r}(t)
\end{array}\right]\right)+\beta \mathbf{D}_{12} \mathbf{u}(t),} \\
\mathbf{y}(t)=\mathbf{C}_{2} \mathbf{x}(t)+\mathbf{D}_{21}\left[\begin{array}{c}
\mathbf{w}(t) \\
\mathbf{r}(t)
\end{array}\right]+\mathbf{D}_{22} \mathbf{u}(t),
\end{array}\right.
$$

де $\mathbf{x}(t)$ - вектор координат стану; $\mathbf{w}(t)$ - вектор зовнішніх збурень; $\mathbf{r}(t)-$ вектор завдання; $\mathbf{u}(t)$ - вектор керування; $\boldsymbol{\varepsilon}(t)=\mathbf{r}(t)-\mathbf{y}(t)-$ вектор розузгодження; $\mathbf{y}(t)$ - вектор вимірювань; матриці $\mathbf{A}, \mathbf{B}_{1}, \mathbf{B}_{2}, \mathbf{C}_{1}, \mathbf{D}_{11}, \mathbf{D}_{12}, \mathbf{C}_{2}$, $\mathbf{D}_{21}, \mathbf{D}_{22}$ мають відповідні розмірності, крім того, більшість 3 них визначаються блочно-діагональною формою виду:

$$
\begin{gathered}
\mathbf{A}=\left[\begin{array}{c}
\mathbf{A}_{n_{\mathbf{x}} \times n_{\mathbf{x}}}^{\mathbf{x}}
\end{array}\right], \mathbf{B}_{1}=\left[\begin{array}{ll}
\mathbf{B}_{n_{\mathbf{x}} \times n_{\mathbf{w}}}^{\mathbf{w}} & \mathbf{0}_{n_{\mathbf{x}} \times n_{\mathbf{r}}}
\end{array}\right], \mathbf{B}_{2}=\left[\mathbf{B}_{n_{\mathbf{x}} \times n_{\mathbf{u}}}^{\mathbf{u}}\right], \\
\mathbf{C}_{1}=\left[\begin{array}{c}
-\mathbf{C}_{n_{\mathbf{y}} \times n_{\mathbf{x}}}^{\mathbf{y}} \\
\mathbf{0}_{n_{\mathbf{u}} \times n_{\mathbf{x}}}
\end{array}\right], \mathbf{C}_{2}=\left[\begin{array}{l}
\mathbf{C}_{n_{\mathbf{y}} \times n_{\mathbf{x}}}^{\mathbf{y}}
\end{array}\right], \\
\mathbf{D}_{11}=\left[\begin{array}{ll}
\mathbf{0}_{n_{\mathbf{r}} \times n_{\mathbf{w}}} & \mathbf{I}_{n_{\mathbf{r}} \times n_{\mathbf{r}}} \\
\mathbf{0}_{n_{\mathbf{u}} \times n_{\mathbf{w}}} & \mathbf{0}_{n_{\mathbf{u}} \times n_{\mathbf{r}}}
\end{array}\right], \mathbf{D}_{12}=\left[\begin{array}{l}
\mathbf{0}_{n_{\mathbf{r}} \times n_{\mathbf{u}}} \\
\mathbf{I}_{n_{\mathbf{u}} \times n_{\mathbf{u}}}
\end{array}\right], \mathbf{D}_{21}=\left[\begin{array}{ll}
\mathbf{0}_{n_{\mathbf{y}} \times n_{\mathbf{w}}} & \mathbf{0}_{n_{\mathbf{y}} \times n_{\mathbf{r}}}
\end{array}\right] ; \mathbf{D}_{22}=\left[\mathbf{0}_{n_{\mathbf{y}} \times n_{\mathbf{u}}}\right] .
\end{gathered}
$$

де $\mathbf{A}_{n_{\mathbf{x}} \times n_{\mathbf{x}}}^{\mathbf{x}}, \mathbf{B}_{n_{\mathbf{x}} \times n_{\mathbf{w}}}^{\mathbf{w}}, \mathbf{B}_{n_{\mathbf{x}} \times n_{\mathbf{u}}}^{\mathbf{u}}, \mathbf{C}_{n_{\mathbf{y}} \times n_{\mathbf{x}}}^{\mathbf{y}}-$ відповідно, матриці чисел, отримані з системи диференціальних рівнянь шляхом ідентифікації об'єкта (нижнім індексом $n_{\mathbf{i}} \times n_{\mathbf{j}}$ позначені розмірності матриць через розмірності векторів $\mathbf{i}$ та $\left.\mathbf{j}\right) ; \mathbf{0}_{n_{\mathbf{i}} \times n_{\mathbf{j}}}-$ матриця нульових чисел, розмірністю $n_{\mathrm{i}} \times n_{\mathrm{j}} ; \mathbf{I}_{n_{\mathrm{i}} \times n_{\mathrm{j}}}-$ одинична матриця, розмірністю $n_{\mathrm{i}} \times n_{\mathrm{j}} ; \alpha, \beta$ - параметри системи керування. Нехай $n_{\mathrm{r}}=n_{\mathbf{y}}=n_{\varepsilon}$. 
В (1) у вектор стабілізованих виходів $[\boldsymbol{\varepsilon}, \mathbf{u}]^{T}$ введений вектор керування для обмеження останнього, причому складові стабілізованих виходів зважені параметрами системи $\alpha$ та $\beta$, що визначають компроміс між якістю та енергозбереженням системи (в загальному вигляді можуть залежати від часу або частоти).

Розглянемо типову структуру робастно-оптимальної системи керування, зображену на рис. 1, що складається з регулятора та об'єкта керування. Регулятор будується за виходами об'єкта:

$$
\mathbf{u}(t)=\mathbf{K}(s) \mathbf{y}(t),
$$

де $\mathbf{K}(s)$ - передавальна функція регулятора, структура та/або параметри якого розраховують шляхом мінімізації $\mathrm{H}_{\infty}$-норми передатної функції замкненої системи $\mathbf{H}(s)$ від вектора входів $[\mathbf{w}, \mathbf{r}]^{T}$ до виходів $[\boldsymbol{\varepsilon}, \mathbf{u}]^{T}$ :

$$
J=\min _{\mathbf{K}(s) \in \Omega}\|\mathbf{H}(s)\|_{\infty}^{2},
$$

де $\Omega$ - область регуляторів, що стабілізують об'єкт.

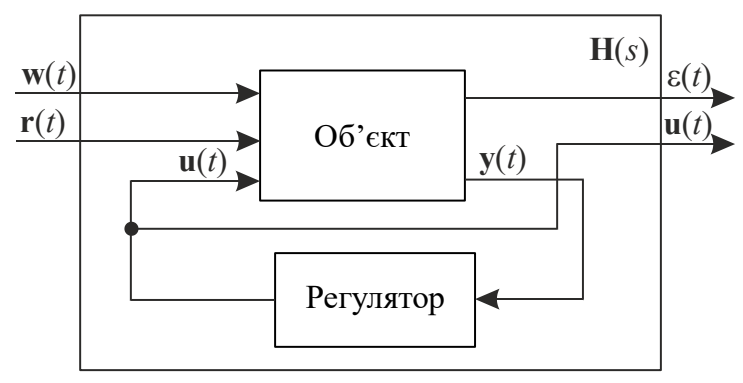

Рис. 1. Структурна схема робастно-оптимальної системи керування

Таким чином отримуємо робастно-оптимальну систему керування, енергоефективність якої можна налаштувати шляхом завдання параметрів $\alpha$ та $\beta$. Передатна функція регулятора обирається з класу стабілізованих (область $\Omega$ ). Обмеженням на $\mathbf{K}(s)$ також може бути структура регулятора, стійкість передатної функції регулятора тощо.

Поставимо задачу оптимізації параметрів $\alpha$ та $\beta$ при заданій структурі регулятора:

$$
J=\min _{\alpha, \beta \in \Omega_{2}} \min _{\mathbf{K}(s) \in \Omega_{1}}\|\mathbf{H}(s)\|_{\infty}^{2},
$$

де $\Omega_{1}$ - задана структура регулятора, що стабілізує об'єкт; $\Omega_{2}$ - задана область параметрів $\alpha$ та $\beta$.

Оптимізаційну задачу (5) можна розширити шляхом введення різних обмежень, виділивши 3 внутрішньої оптимізаційної задачі частковий критерій. Тоді оптимізаційну задачу можна записати так: 


$$
\begin{aligned}
J= & \left.\min _{\alpha, \beta \in \Omega_{2},}\left[\min _{\mathbf{K}(s) \in \Omega_{1}}\|\mathbf{H}(s)\|_{\infty}^{2}\right]\right|_{\mathbf{u w}}, \\
& \left\|\mathbf{H}_{\mathbf{z w}}(s)\right\|_{\infty} \leq \gamma, \\
& \left\|\mathbf{H}_{\mathrm{er}}(s)\right\|_{\infty} \leq 1,
\end{aligned}
$$

де [] $\left.\right|_{\text {uw }}$ позначено $\mathrm{H}_{\infty}$-норму від вектора зовнішніх збурень до вектора керувань $\mathbf{u} ; \gamma-$ обмеження на $\mathrm{H}_{\infty}$-норму від вектора зовнішніх збурень $\mathbf{w}$ до вектора розузгодження $\boldsymbol{\varepsilon}$, що визначаються 3 технологічного регламенту ведення процесу.

Обираючи критерій (6), проектант системи автоматизації задає лише $\gamma$, таким чином мінімізуючи $\mathrm{H}_{\infty}$-норму від вектора зовнішніх збурень $\mathbf{w}$ до вектора керувань $\mathbf{u}$, тобто мінімізуються витрати робастно-оптимальної системи керування.

Для завдання області $\Omega_{2}$ можливі варіанти:

- область дійсних чисел $\left(\alpha, \beta \in R^{n}\right)$, причому $\alpha+\beta=1, \alpha, \beta>0$;

- область параметрів заданих стійких дробово-раціональних передавальних функції:

$$
\begin{gathered}
\left(\alpha(s)=\frac{A(s)}{B(s)}=\frac{1+a_{1} s+a_{2} s^{2}+\ldots+a_{n_{a}} s^{n_{a}}}{1+b_{1} s+b_{2} s^{2}+\ldots+b_{n_{b}} s^{n_{b}}},\right. \\
\left.\beta(s)=\frac{C(s)}{D(s)}=\frac{1+c_{1} s+c_{2} s^{2}+\ldots+c_{n_{c}} s^{n_{c}}}{1+d_{1} s+d_{2} s^{2}+\ldots+d_{n_{d}} s^{n_{d}}}, n_{a} \leq n_{b}, n_{c} \leq n_{d}\right) ;
\end{gathered}
$$

- область стійких дробово-раціональних передавальних функції:

$$
\left(\alpha(s), \beta(s) \in R H_{\infty}\right) .
$$

Останні рекомендується задавати не вище 3-го порядку, оскільки підвищення порядку призводить до збільшення коливань керуючого сигналу та зношення регулюючого органу.

Аналітично розв'язок задачі (6) знайти проблематично, тому використовуються ітераційні методи пошуку. Крім того, оптимізаційна задача (6) негладка, тому ефективним буде використання випадкових методів пошуку або методів повного перебору. Ці ж методи рекомендується застосовувати при структурній оптимізації вагових параметрів $\alpha(s)$ та $\beta(s)$ шляхом поступового збільшення порядку поліномів $A(s), B(s), C(s), D(s)$. Стосовно внутрішньої оптимізаційної задачі (6), тобто (4), то рекомендується застосовувати методи, наведені в таблиці.

Приклад. Змоделюємо робастно-оптимальну систему керування з різними значеннями параметрів $\alpha$ та $\beta$ для підсистеми керування рівнями багатокорпусної випарної установки цукрового заводу, математична модель та особливості синтезу якої наведені в [10]. Математична модель об'єкта описується системою диференціальних рівнянь 5-го порядку, а структура регулятора статична матриця розмірності $5 \times 5$. 
Нехай $\alpha$ та $\beta$ дійсні числа та $\alpha+\beta=1, \alpha, \beta>0$. Тоді шляхом синтезу робастнооптимальної системи керування з різними значеннями $\alpha$ та $\beta$ отримаємо графіки зміни критерію керування. Задача оптимізації розв'язувалася в пакеті прикладних програм Matlab, бібліотека Robust Control Toolbox. На рис. 2а зображено зміну критерію керування за ітераціями, якщо критерієм керування є $\left\|\mathbf{H}_{\mathbf{u w}}(s)\right\|_{\infty}$ та наявні лише обмеження на $\alpha$ та $\beta$. На рис. $2 б$ критерієм $\epsilon$, відповідно, $\left\|\mathbf{H}_{\varepsilon \mathbf{w}}(s)\right\|_{\infty}$. Як бачимо, другий критерій суттєво нелінійний з немонотонною властивістю. Задавши значення $\gamma$, отримуємо проміжні значення параметрів $\alpha$ та $\beta$.
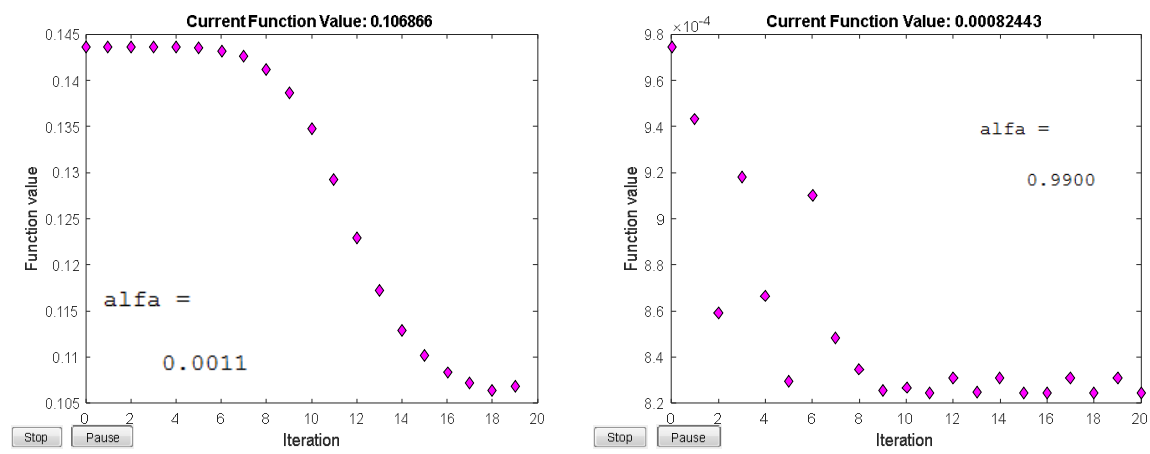

Рис. 2. Зміна критерію керування за ітераціями:

a - мінімізація $\left\|\mathbf{H}_{\mathrm{uw}}(s)\right\|_{\infty} ; \sigma$ - мінімізація $\left\|\mathbf{H}_{\mathrm{zw}}(s)\right\|_{\infty}$

На рис. 3. наведено область компромісу між критеріями якості та енерговитрат робастно-оптимальної системи керування. Оптимальне значення параметра $\alpha$ можна знайти, використовуючи критерій:

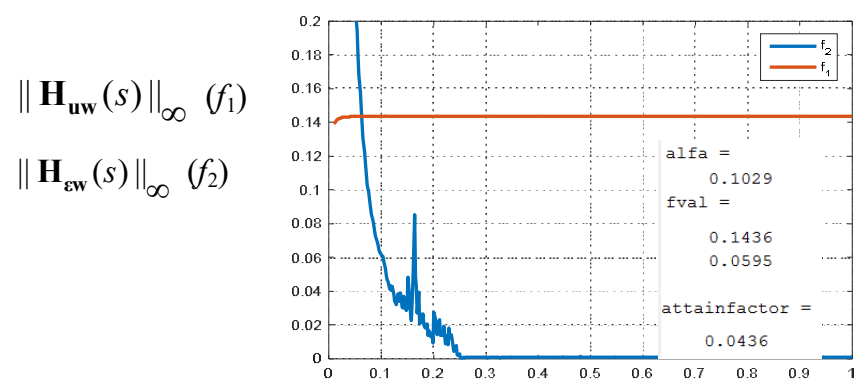

Рис. 3. Залежність критеріїв від параметра $\alpha$

$$
J=\min _{\alpha \in \Omega_{2}}, \zeta \text { за умов }\left\{\begin{array}{l}
{\left[\begin{array}{l}
\left\|\mathbf{H}_{\mathbf{u w}}(s)\right\|_{\infty} \\
\left\|\mathbf{H}_{\mathrm{zw}}(s)\right\|_{\infty}
\end{array}\right]-\left[\begin{array}{l}
1 \\
1
\end{array}\right] \zeta \leq \text { goal; }} \\
\alpha_{\min } \leq \alpha \leq \alpha_{\max } ; \beta=1-\alpha,
\end{array}\right.
$$

де $\mathbf{H}_{\mathbf{u w}}(s)$ та $\mathbf{H}_{\boldsymbol{\varepsilon}}(s) \in$ блочними матрицями 3 матриці $\mathbf{H}(s)$, що розраховується шляхом розв'язання задачі оптимізації $\min \|\mathbf{H}(s)\|_{\infty}^{2} ;$ goal — $\mathbf{K}(s) \in \Omega_{1}$ 
вектор цілей (наприклад $\left.[0.10 .1]^{T}\right) ; \zeta$ — фактор досягнення цілей (attainfactor). Для наведеного прикладу розраховані значення задачі (7) (рис. 3). Аналізуючи отримані результати, слід зазначити, що компроміс виправданий, оскільки критерій енерговитрат $\left(f_{1}\right)$ мало змінюється при $\alpha>0.11$, а подальше зменшення критерію якості $\left(f_{2}\right)$ призводить до нестабільності.

Завдяки використанню критерію (7) перед проектантом системи автоматизації знімається альтернатива вибору між енерговитратами та якістю системи автоматизації.

\section{Висновки}

При синтезі робастно-оптимальних регуляторів для технологічних об'єктів, що працюють в умовах дії суттєвих невизначеностей, постає питання забезпечення компромісу між енерговитратами та якістю системи регулювання в динамічному режимі, що в цілому забезпечить енергоефективність системи. Це питання має суб'єктивний характер і цілком залежить від проектанта. Однак можна ввести в математичну модель системи вагові параметри та побудувати оптимізаційні задачі їх вибору на основі критеріїв (5)-(7). Наведений приклад розв'язку такої задачі довів свою ефективність.

Завдяки отриманим ваговим параметрам компромісу між енерговитратами та якістю системи керування при мінімізації сформованих критеріїв знімається альтернатива вибору, що стоїть перед проектантом системи керування, а отримана система в цілому забезпечить енергоефективність системи. Подальші дослідження направлені на пошук ефективних ітераційних методів пошуку поставлених оптимізаційних задач для скорочення об'єму та часу обчислення.

\section{Література}

1. Методы классической и современной теории автоматического управления: Учебник в 5 т. / Под ред. К.А. Пупкова, Н.Д. Егупова. Москва: Издательство МГТУ им. Н.Э. Баумана, 2004. Т. 3. $616 \mathrm{c}$.

2. Ricardo S. Sánchez-Peñaand, Mario Sznaier. Robust Systems: Theory and Applications. Wiley: New York, 1998. 490 p.

3. Поляк Б.Т., Щербаков П.С. Робастная устойчивость и управление. Москва: Наука, 2002. $303 \mathrm{c}$.

4. McFarlane D.C., Glover K. Robust Controller Design using Normalised Coprime Factor Plant Descriptions. Springer Verlag: Lecture Notes in Control and Information Sciences. 1989. Vol. 138.

5. McFarlane D.C., Glover K. A Loop Shaping Design Procedure using Synthesis. IEEE Transactions on Automatic Control. 1992. 37(6). P. 759-769.

6. Поляк Б.Т., Хлебников М.В., Щербаков П.С. Управление линейными системами при внешних возмущениях: Техника линейных матричных неравенств. Москва: ЛЕНАНД, 2014. $560 \mathrm{c}$.

7. Apkarian P., Noll D. Nonsmooth H-infinity Synthesis. IEEE Transactions on Automatic Control. 2006. 51(1), P. 71-86.

8. Apkarian P., D. Noll, D. Alazard. Controller Design via Nonsmooth Multi-Directional Search. IFAC Conf. on System Structure and Control. 2004. Vol. 44, No. 6. P. 1923-1949.

9. Morari M., Zafiriou E. Robust process control. Prentice Hall, 1989. 488 p.

10. Ладанюк А.П., Луцкая Н.Н. Особенности задач робастного управления технологическими объектами. Часть 1. Технологические объекты и их математические модели. Проблемы управления и информатики. 2016. № 5. С. 16-23. 